\title{
Dopamine Receptor Subtypes Selectively Modulate Excitatory Afferents from the Hippocampus and Amygdala to Rat Nucleus Accumbens Neurons
}

\author{
A Charara*,' and AA Grace' \\ 'Departments of Neuroscience and Psychiatry, University of Pittsburgh, Pittsburgh, PA, USA
}

\begin{abstract}
The nucleus accumbens (NAc) receives excitatory afferents from several cortical and limbic regions and dense dopaminergic inputs from the ventral tegmental area. We examined the effects of dopamine (DA) DI and D2 selective drugs on the responses evoked in the NAc shell neurons recorded in vitro by stimulation of hippocampal and amygdaloid afferents. Activation of hippocampal and amygdaloid afferents induced excitatory postsynaptic responses that were depressed by bath application of DA in most of the cells recorded. The DA effect was substantially blocked by the DI receptor antagonist SCH 23390, but not by the D2 receptor antagonist eticlopride. Moreover, the DI receptor agonist SKF 38393, but not the D2 receptor agonist quinpirole, mimicked the effects of DA, although a small population of neurons exhibited a DI-mediated facilitation of the EPSP amplitude following fornix stimulation. These data demonstrate a DA receptor subtype-specific modulation of glutamatergic inputs to the NAc, with DI agonists attenuating amygdaloid inputs, whereas hippocampal-evoked responses were either depressed or potentiated by DI stimulation. Such facilitation or attenutation of hippocampal afferents against a background of suppression of other afferents would permit the hippocampus to have a dominant influence over behavior during periods of exploration.

Neuropsychopharmacology (2003) 28, | 4I2- |42I, advance online publication, I I June 2003; doi: I 0. I 038/sj.npp. I 300220
\end{abstract}

Keywords: nucleus accumbens; dopamine; hippocampus; amygdala; afferents; in vitro

\section{INTRODUCTION}

The nucleus accumbens (NAc), which is the principal component of the ventral striatum, is central to the limbic system and is thought to play a role in the translation of limbic information into goal-directed behavior. Indeed, the NAc receives excitatory glutamatergic inputs primarily from limbic-related structures, including the hippocampus, basolateral amygdala (BLA), prefrontal cortex (PFC), and various thalamic nuclei (Sesack et al, 1989; Berendse and Groenewegen, 1990; Callaway et al, 1991; Pennartz et al, 1994; Finch, 1996). The NAc is also densely innervated by dopaminergic afferents originating in the ventral tegmental area (VTA) (Nauta et al, 1978). In many instances, these inputs converge on the same accumbal neurons (Sesack and Pickel, 1990, 1992; O’Donnell and Grace, 1995; Mulder et al, 1998). In turn, the NAc projects to areas involved in motor

*Correspondence: Dr A Charara, Department of Neuroscience, University of Pittsburgh, 446 Crawford Hall, Pittsburgh, PA I5260, USA, Tel: + I 4I2 624 8895, Fax: + I 4126249198 ,

E-mail: charara@brain.bns.pitt.edu

Received I4 January 2003; revised 01 April 2003; accepted 03 April 2003

Online publication: 28 April 2003 at http://www.acnp.org/citations/ Npp042802022/default.pdf output such as the ventral pallidum, which influences several limbic-related thalamocortical circuits (Heimer and Alheid, 1991). A major target of the accumbens-ventral pallidal system is the mediodorsal nucleus of the thalamus (Lavin and Grace, 1994), which provides the major regulatory control over the PFC. The two main limbic input structures of the NAc can be assigned to distinct behaviors. The amygdala forms a link between sensory systems and structures involved in emotional behavior (Davis, 1992; Ledoux, 1993), whereas the hippocampus is important in memory tasks, particularly those involving spatial cues and context-dependent behaviors (Alvarez et al, 1995).

Dopaminergic neurotransmission within the NAc has received particular attention because of its role in promoting locomotion (Iversen, 1995), motivation and reward (Robbins and Everitt, 1996), and addiction and sensitization to drugs of abuse (Kalivas et al, 1993). Many behavioral studies have suggested that interactions between DArgic and glutamatergic inputs into the NAc contribute to this variety of psychomotor behaviors (Kalivas et al, 1993; Hyman, 1996; Robbins and Everitt, 1996). Ultrastructural studies of the NAc have found DArgic terminals apposed to both symmetrical and asymmetrical synapses (Sesack and Pickel, 1992), as well as a significant proportion unapposed to any postsynaptic structures (Bouyer et al, 1984; 
Descarries et al, 1996). Thus, dopaminergic afferents to the NAc may modulate synaptic transmission either by releasing dopamine (DA) directly onto synapses or by causing a more diffuse increase in extracellular DA levels (Garris et al, 1994; Grace, 1991; Descarries et al, 1996).

Many electrophysiological studies have examined the effects of DA on synaptic transmission in the NAc. In vivo studies reported that VTA stimulation, DA iontophoresis, or DArgic drug administration reduced stimulus-evoked excitatory responses from either hippocampal or amygdaloid afferents (Yang and Mogenson, 1984; DeFrance et al, 1985; Yim and Mogenson, 1986, 1989; Floresco et al, 2001a,b). Moreover, studies using in vitro brain slice preparations of the NAc consistently demonstrated that DA and psychostimulants depress excitatory synaptic transmission (Pennartz et al, 1992b; Harvey and Lacey, 1996; O’Donnell and Grace, 1994). However, little is known regarding the relative contribution of D1- and D2-like receptors to the modulation of excitatory inputs from the hippocampus and amygdala to NAc spiny neurons (Harvey and Lacey, 1996; Groenewegen et al, 1999; Nicola et al, 2000). In order to understand how DA modulates amygdalar and hippocampal inputs to NAc neurons, we examined the effects of DArgic drugs on the responses evoked by selectively stimulating each of these inputs in an in vitro brain slice preparation optimized to enable the activation of each afferent system. A portion of this work has been published in abstract form (Charara and Grace, 2001).

\section{MATERIALS AND METHODS}

\section{Tracer Injections-Light Microscopy}

The courses of projection of hippocampal and amygdalar pathways to the NAc were analyzed using tracer injections to label afferent inputs. These studies were performed in male Sprague-Dawley rats weighing 250-300 g (Hilltop Laboratories, Scott-Dale, PA). Surgical procedures were carried out with animals under anesthesia with chloral hydrate $(400 \mathrm{mg} / \mathrm{kg}$, i.p.). All procedures were performed in accordance with the Guide for the Care and Use of Laboratory Animals published by the United States Public Health Services, with the experimental protocol approved by the University of Pittsburgh Institutional Animal Care and Use Committee. All efforts were made to minimize the number of animals used and their suffering.

In two rats (four hemispheres), bilateral injections of biocytin ( $4 \%$ in potassium acetate buffer; Sigma) were sterotaxically placed in the amygdala (coordinates with respect to bregma: $\mathrm{AP}-2.8$ and $-3.3 \mathrm{~mm}, \mathrm{ML}+5.0$ and $+4.6 \mathrm{~mm}$, and DV $-8.4 \mathrm{~mm}$ ) or subiculum (AP -5.0 and $-5.3 \mathrm{~mm}$ from bregma; $\mathrm{ML}+0.9$ and $+1.2 \mathrm{~mm}$, and $\mathrm{DV}$ $-3.6 \mathrm{~mm}$ from the dura). The biocytin was iontophoretically delivered through glass micropipettes with a tip diameter ranging from 15 to $25 \mu \mathrm{m}$ using $5 \mu \mathrm{A}$ anodal current ( $7 \mathrm{~s}$ on, $7 \mathrm{~s}$ off) for $15-20 \mathrm{~min}$. The animals were deeply anesthetized $48 \mathrm{~h}$ after the injection and perfused transcardially with $100 \mathrm{ml}$ of Ringer's solution, followed by $300 \mathrm{ml}$ of fixative containing $4 \%$ paraformaldehyde and $0.1 \%$ glutaraldehyde in phosphate buffer $(\mathrm{PB} ; 0.1 \mathrm{M}, \mathrm{pH}$ 7.4). Free aldehydes were then removed by perfusion with $100 \mathrm{ml}$ of $10 \%$ sucrose in $0.1 \mathrm{M} \mathrm{PB}$. The brains were removed and stored in $30 \%$ sucrose solution until they sank. The fixed brains were then cut sagittally or horizontally with a freezing microtome into $80 \mu \mathrm{m}$-thick sections. After careful rinsing with phosphate-buffered saline (PBS; $0.05 \mathrm{M}, \mathrm{pH} 7.4$ ), the sections were incubated for $12 \mathrm{~h}$ at $4{ }^{\circ} \mathrm{C}$ in avidin-biotin-peroxidase complex (ABC 1:100; Vector labs) containing $0.3 \%$ Triton $\mathrm{X}-100$ and $1 \%$ bovine serum albumin. After washing three times with PBS, the sections were incubated for $10 \mathrm{~min}$ in a mixture of diaminobenzidine (DAB) and $\mathrm{H}_{2} \mathrm{O}_{2}$. These sections were then mounted on gelatin-coated slides, air-dried, and a coverslip was applied with Permount. The sections were examined with bright field illumination using a Leitz microscope. For illustration purposes, the injection sites and the distribution of antergogradely labeled fibers were transferred onto standard drawings of the rat brain (Paxinos and Watson, 1986).

\section{Electrophysiology}

Intracellular recordings were made from medium spiny neurons in the slices as described previously (O'Donnell and Grace, 1993). Briefly, rats (male Sprague-Dawley, 200$300 \mathrm{~g}$ ) were deeply anesthetized with chloral hydrate $(400 \mathrm{mg} / \mathrm{kg}$, i.p.) before transcardial perfusion with ice-cold physiological saline solution $(229 \mathrm{mM}$ sucrose, $1.9 \mathrm{mM} \mathrm{KCl}$, $1.2 \mathrm{mM} \mathrm{Na}_{2} \mathrm{HPO}_{4}, 33.3 \mathrm{mM} \mathrm{NaHCO} 3,20 \mathrm{mM}$ glucose, and $6 \mathrm{mM} \mathrm{MgCl}_{2}$ ) oxygenated with a mixture of $95 \% \mathrm{O}_{2}$ and $5 \%$ $\mathrm{CO}_{2}$. The brains were then quickly removed and $300 \mu \mathrm{m}$ thick slices containing the NAc were cut either in the horizontal or sagittal plane using a vibratome, while submerged in the physiological saline solution. Slices containing the NAc were stored at least $1 \mathrm{~h}$ at room temperature in continuously oxygenated physiological saline (124 mM NaCl, $5 \mathrm{mM} \mathrm{KCl}, 1.2 \mathrm{mM} \mathrm{KH}_{2} \mathrm{PO}_{4}, 2.4 \mathrm{mM}$ $\mathrm{CaCl}_{2}, 1.3 \mathrm{mM} \mathrm{MgSO}_{4}, 26 \mathrm{mM} \mathrm{NaHCO}_{3}$, and $10 \mathrm{mM}$ glucose) saturated with $95 \% \mathrm{O}_{2}: 5 \% \mathrm{CO}_{2}$.

Intracellular recordings were performed using a submersion-type recording chamber (Warner Inst. Corp., RC-22) that was superfused $(2 \mathrm{ml} / \mathrm{min})$ with oxygenated physiological saline maintained at $34^{\circ} \mathrm{C}$ using a peristaltic pump (Haake-Büchler, MCP 2500). The time required for the complete exchange of media within the chamber was $3 \mathrm{~min}$. Sharp electrodes were constructed from $1 \mathrm{~mm}$ OD Omegadot borosilicate glass tubing (World Precision Instruments, New Haven, CT) using a horizontal puller (Flaming-Brown $\mathrm{P}-80 / \mathrm{PC}$ ). The electrodes were filled with $3.0 \mathrm{M}$ potassium acetate or, in some cases, with $2 \%$ biocytin (Sigma, St Louis, MO) and had resistances of 55-100 M $\Omega$ measured in situ. Afferent fibers were stimulated using bipolar electrodes constructed from a pair of enamel-coated nichrome wires twisted together with the insulation at the tip removed to expose $0.5 \mathrm{~mm}$ of wire. Stimulation of afferent fibers was performed using $50 \mu \mathrm{A}-1.2 \mathrm{~mA}$ constant current pulses that were $100-500 \mu \mathrm{s}$ in duration. In order to stimulate the hippocampal and amygdaloid afferents innervating accumbal shell neurons, the electrode tips were placed gently on the surface of the slice in contact with the fornix and bed nucleus of the stria terminalis, respectively. The location of the recording site and the stimulating electrode were determined by visual inspection using a stereomicroscope (Nikon SMZ-2B), with the shell division of the NAc 
identified according to the rat brain stereotaxic atlas of Paxinos and Watson (1986).

The electrodes were connected to the headstage of a NeuroData intracellular amplifier (Neurodata IR-183). Current was injected into neurons through a bridge circuit integral to the amplifier, with the current injection amplitude and the electrode voltage monitored on an oscilloscope (Kikusui COS5020-ST). Data were digitized using a NeuroData Neurorecorder (DR-886) and stored on VHS videotapes for subsequent off-line analysis. In addition, data were also digitized using a Microstar interface board prior to storage on a hard disk drive and off-line analysis. The analysis was performed using custom software (Neuroscope) running on a Windows-based PC computer. The input resistance was measured by injecting a series of hyperpolarizing constant current pulses of increasing amplitude (100-150 ms in duration) into the cell and measuring the resultant deflections in membrane potential.

All drugs were dissolved in the superfusion media and applied into the recording chamber. After obtaining stable baseline data and recording the responses to intracellular current injection and electrical stimulation of afferent fibers, the perfusion lines were switched from control to the drug-containing solutions, while maintaining stable perfusion pressure and fluid volume via the peristaltic pump delivery system. The drugs used were: DA (30$60 \mu \mathrm{M})$, SCH $23390(3-5 \mu \mathrm{M})$, eticlopride $(10 \mu \mathrm{M})$, SKF $38393(10 \mu \mathrm{M})$, and quinpirole $(10 \mu \mathrm{M})$. Ascorbic acid $(0.02 \%)$ was added to the DA-containing solution to prevent oxidation of DA. To rule out any potential confounds related to the physiological actions of ascorbic acid, both control and DA-containing solutions contained the antioxidant. Since the time required for media exchange was $3 \mathrm{~min}$, measurements of the drug effects were initiated following 1-2 $\mathrm{min}$ of exposure to drugs (ie 4-5 min after switching perfusion lines), at which point, a steady-state concentration of the drug in the chamber should have been achieved. The responses to the application of DA and DA agonists for a period of $1 \mathrm{~min}$ were similar to those observed after a prolonged application $(3 \mathrm{~min})$. Therefore, we chose 1-2 min of application to obtain a sufficient reproducibility of the response. Drug effects were evaluated by comparing the main peak value of EPSPs during the control (immediately before drug perfusion), drug application, and washout period (10-20 min). The statistical significance of drug-induced changes in measures of responses was determined using a paired Student's $t$-test.

\section{RESULTS}

\section{Hippocampus-NAc pathway}

In order to label most of the hippocampo-accumbal projections, two biocytin deposits were placed in the subiculum (Kelley and Domesick, 1982; Canteras and Swanson, 1992). This was performed to identify the course of fibers projecting to the NAc within the sagittal plane, since a considerable amount of the published anatomical data that described the topographical organization of the projections from the hippocampus to the NAc in rats was based on coronal sections (Kelley and Domesick, 1982; Groenewegen et al, 1987). The injection sites were confined

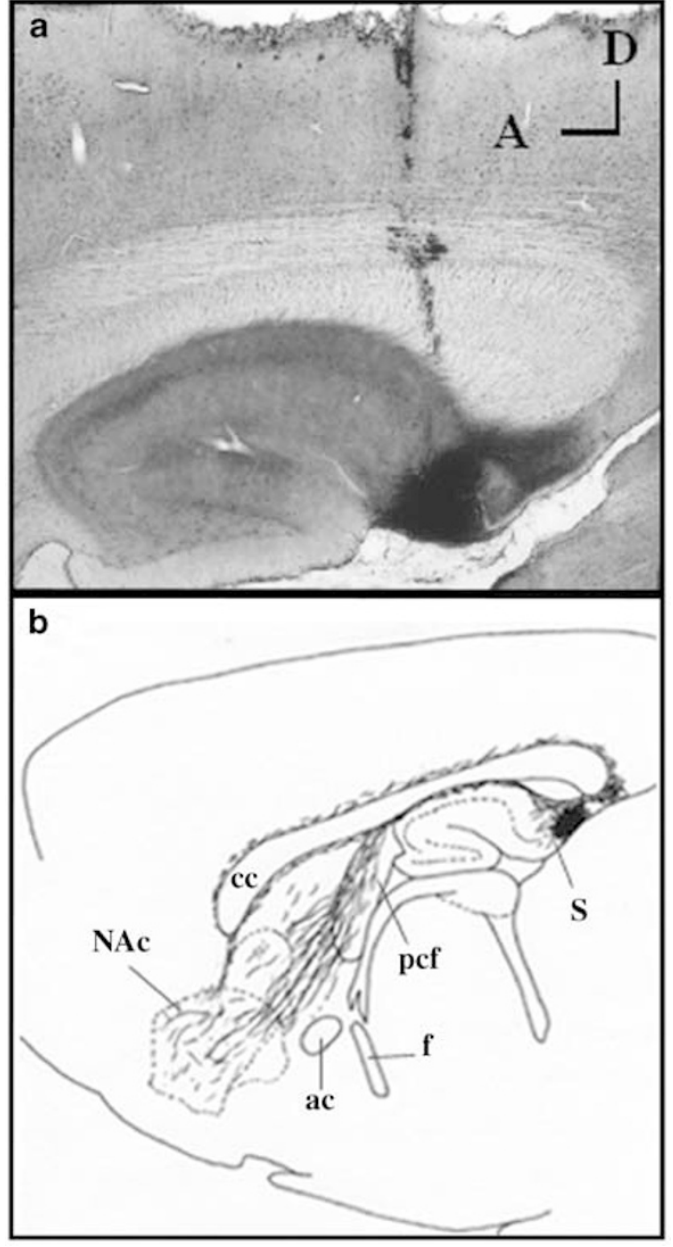

Figure I Hippocampal projection to the NAc. (a) Sagittal view of the rat hippocampus showing an injection site of biocytin in the subiculum. (b) A schematic drawing, in the sagittal plane, showing the pathway of biocytinlabeled fibers that leave the hippocampus and project to the NAc.

to the subiculum and did not spread to adjacent areas (Figure 1a).

In a representative case, a major bundle of fibers is observed to arise from the injection site in the subiculum (Figure 1a,b). The fibers first enter the alveus, course dorsally and then run in the rostral direction through the fimbria/fornix. In the medial sections of the NAc, these fibers were seen to leave the postcommissural fornix en route to innervate the lateral septum and NAc as well as PFC, as described previously (Kelley and Domesick, 1982; Groenewegen et al, 1987; Jay and Witter, 1991). The fibers enter the NAc via the dorsal portion of the nucleus where they branch extensively, forming fine ramifications with varicosities, which probably represent axonal terminals. A schematic illustration of the course of the pathway is depicted in Figure 1. Thus, a sagittal plane of section was chosen to maximally preserve the hippocampal projection to the shell region of the NAc.

\section{Amygdala-NAc Pathway}

It is well known that the bulk of amygdalofugal projections terminating in the NAc take origin in the BLA and run 


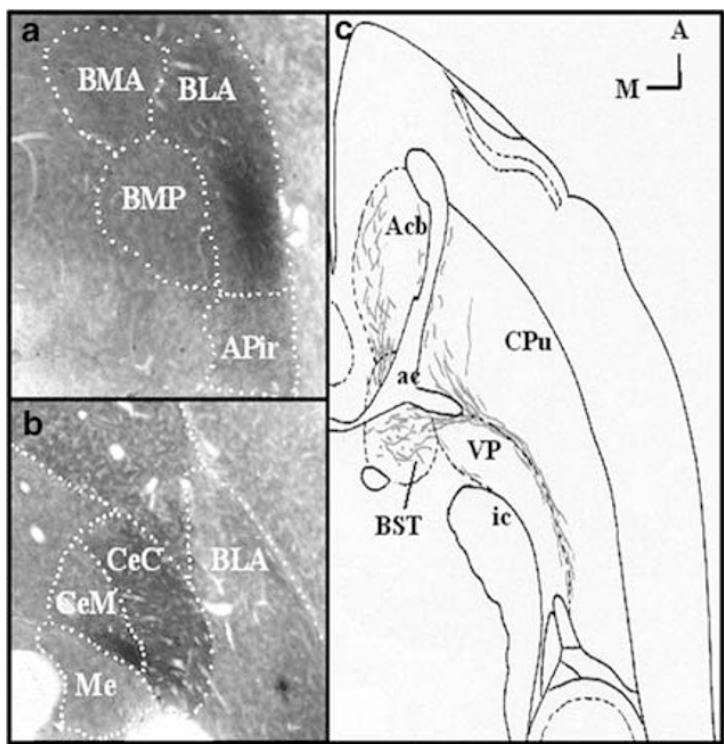

Figure 2 Amygdalar projection to the NAc. (a) and (b) are low power photomicrographs, in the horizontal plane, showing the injection sites of biocytin in the basolateral (a) and central (b) amygdala nuclei. (c) A schematic diagram of labeled fibers leaving the amygdala en route to the NAc.

through the stria terminalis (Kelley et al, 1982; McDonald, 1991). In an attempt to develop a brain slice preparation that preserves this amydala-accumbens pathway, horizontal and sagittal sections were tested. In one representative case, a large biocytin injection site was confined to the lateral part of the BLA (Figure 2a), although a smaller one could be seen in the central nucleus (Figure 2b). The biocytin deposits did not spread over adjacent areas. Pyramidal or piriform neurons with numerous dendrites were labeled around the injection site. From the injection site, labeled fibers extend in several directions, but for the present purpose, only those passing to the NAc and some adjoining subcortical structures were analyzed.

Over ventral sections, many amygdalofugal fibers traveled rostralward along the lateral edge of the ventral pallidum. From this bundle, fibers run through the ventral part of the NAc en route towards the olfactory bulb, although some of these fibers give off collaterals in the NAc and VP. Another major number of fibers exited the BLA and courses medially to join the stria terminalis. In more dorsal sections, fibers coursing through the stria terminalis reach the bed nucleus. Some of these fibers enter the medial part of the Nac, where they gave rise to thin branches bearing many large varicosities. A schematic illustration of the course of the pathway is depicted in Figure 2. Only horizontal sections are presented here since coronal and sagittal sections severed most of the amygdaloid fibers projecting to the NAc.

\section{Membrane Properties and Morphology of Recorded Neurons}

The data were collected from a total of 79 neurons that were located in the shell of the NAc, maintained a steady-state membrane potential greater than $-55 \mathrm{mV}$, and had spike amplitudes greater than $60 \mathrm{mV}$. None of the cells exhibited spontaneous activity. However, spikes could be induced by injecting current pulses of $100-300 \mu \mathrm{s}$ in duration and ranging from 0.1 to $0.7 \mathrm{nA}$. The resting membrane potential (RMP) ranged from -55 to $-91 \mathrm{mV}$ with a mean of $-76 \pm 2.4 \mathrm{mV}$ (SEM; $n=79$ ). The input resistance, estimated by injecting small amplitude hyperpolarizing current pulses $(0.1-0.7 \mathrm{nA})$ and measuring the resultant membrane deflections, averaged $45.3 \pm 1.4 \mathrm{M} \Omega(n=79)$. The spike threshold, estimated by injection of depolarizing current pulses, averaged $42 \pm 2.1 \mathrm{mV}$. The action potentials generated in response to the injection of the depolarizing current were $1.4 \pm 0.2 \mathrm{~ms}$ in duration and $65 \pm 1 \mathrm{mV}$ in amplitude $(n=79)$. Inward rectification in the hyperpolarizing direction was present in 43 of the 79 neurons tested.

Overall, 26 out of 39 of the biocytin-filled neurons were identified as medium spiny projection neurons (Figure $3 \mathrm{c}$ ). They had a soma diameter ranging from 13 to $21 \mu \mathrm{m}$ and exhibited a variety of shapes: multipolar, oval, or fusiform. Three to five primary dendrites emerged from the cell body and the distal dendrites were covered with spines. The axons originated from the soma or from one of the primary dendrites and branched profusely within the dendritic field of the parent cell. The remaining neurons were not sufficiently labeled to clearly distinguish dendritic spines, but exhibited similar somatal size. The labeled neurons formed a sample of the total number of recorded neurons in the present study. The nonfilled cells exhibited similar physiological properties as those neurons identified mor-

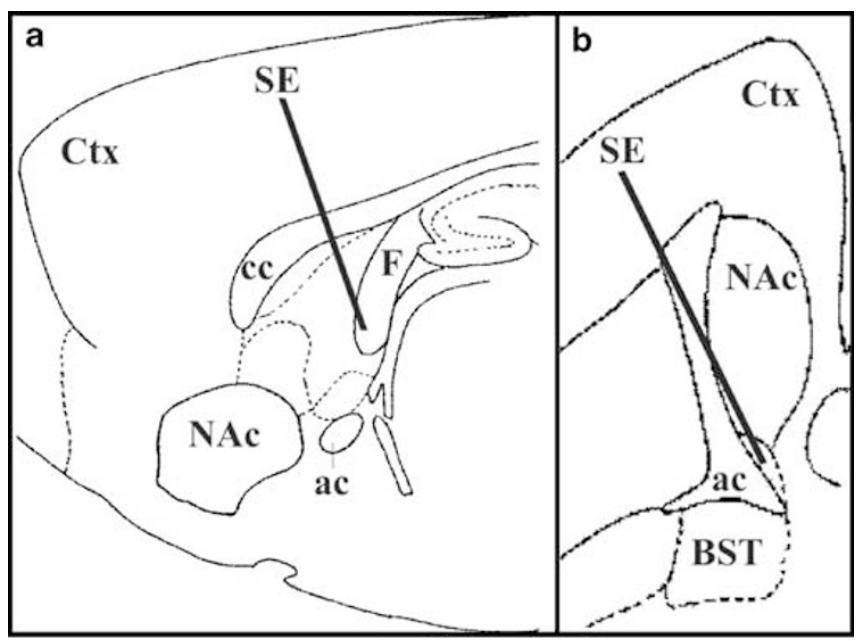

C

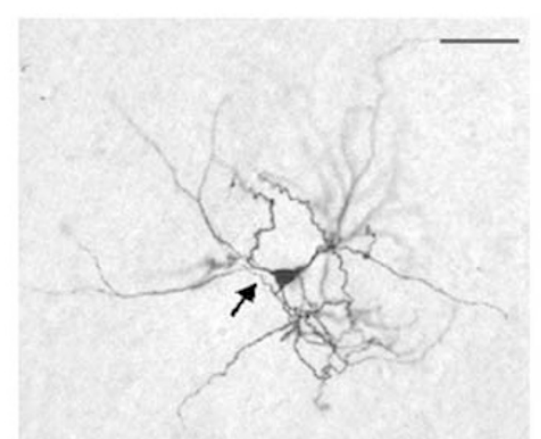

Figure 3 Line drawings illustrating the location of the stimulating electrodes in the fornix (a) and bed nucleus of stria terminalis (b). (c) A photomicrograph of an accumbens neuron that has been labeled by intracellular injection of biocytin following recording. The arrow indicates the axon emerging from the soma. Scale bar $=50 \mu \mathrm{m}$. 
a

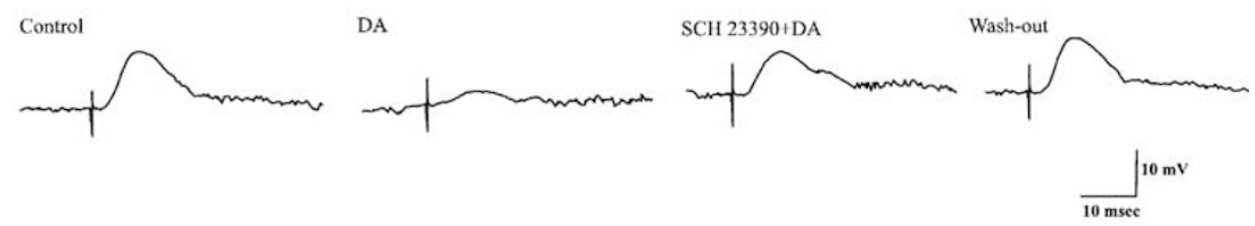

b

Control

D1 agonist (SKF 38393)

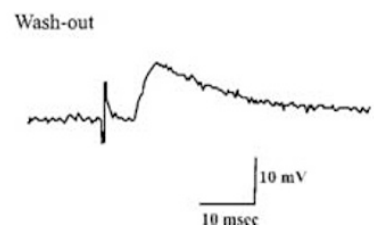

Figure 4 EPSPs evoked by fornix stimulation are attenuated by DI receptor stimulation. (a) DI receptor antagonist SCH $23390(3 \mu \mathrm{M})$ partially reversed the DA $(30 \mu \mathrm{M}$ )-induced reduction of the EPSP evoked by hippocampal stimulation. (b) In another cell, the DI receptor agonist SKF 38393 (I0 $\mu \mathrm{M}$ ) mimicked the effect of DA in that it attenuated the response to fimbria stimulation.

phologically as medium-sized spiny neurons after labeling with biocytin.

\section{DA Effects on Membrane Properties of Nac Neurons}

Previous studies have shown that DA application to NAc neurons produces three types of responses: that is, a biphasic response consisting of an initial hyperpolarization followed by a depolarization, and a monophasic response that was either hyperpolarizing or depolarizing in polarity (Uchimura et al, 1986). Similary, upon perfusion with DA $(30-60 \mu \mathrm{M})$, the majority of NAc neurons tested in the present study (18 out of 35 cells) exhibited a membrane depolarization, although a few neurons exhibited either a membrane hyperpolarization (one out of 35) or a hyperpolarization followed by a depolarization (four out of 35). The remaining neurons were not affected. The membrane depolarization produced by $\mathrm{DA}$ ranged from 2 to $16 \mathrm{mV}$. These changes in membrane potential occurred without a corresponding change in the average input resistance, which was $45 \pm 2 \mathrm{M} \Omega$ in control conditions and $44 \pm 1.8 \mathrm{M} \Omega$ during perfusion with DA. However, in a subset of neurons (three out of 12), the depolarization was accompanied by an increase in input resistance $(46 \pm 1.1 \mathrm{M} \Omega$ in controls compared to $52 \pm 2 \mathrm{M} \Omega$ postDA). These observations were consistent with our previous results (O'Donnell and Grace, 1996). Administration of the selective D1 agonist SKF $38393(10 \mu \mathrm{M} ; n=27)$ induced either a depolarization $(n=11)$ or an initial hyperpolarization and a subsequent depolarization $(n=4)$. On the other hand, administration of the selective D2 agonist quinpirole $(10 \mu \mathrm{M})$ induced a hyperpolarization in six out of eight neurons tested. The remaining neurons were not affected. As observed with DA, in a subset of neurons, the depolarization was accompanied by an increase in input resistance (four out of 11), whereas the hyperpolarization was associated with a decrease in input resistance (three out of six).

\section{DArgic Modulation of Hippocampal-Evoked Responses}

When the rostro-ventral part of the fornix was stimulated electrically (Figure 3a), an excitatory postsynaptic potential

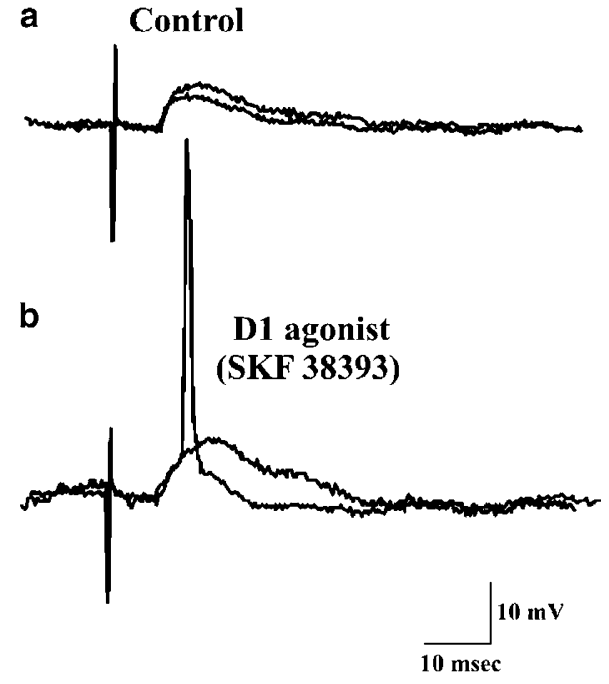

Figure $\mathbf{5}$ In 13\% of the neurons tested, DI receptor stimulation facilitated fornix-evoked responses. (a) Overlay of two responses evoked in a NAc neuron after stimulation of the fimbria with 800 and $1000 \mu \mathrm{A}$ current pulses (300 ms duration). (b) The DI receptor agonist SKF 38393 $(10 \mu \mathrm{M})$ caused an increase in the amplitude of the evoked EPSPs in comparison to control, after stimulation of the fimbria with the same current intensities.

(EPSP) was recorded in 29 of 35 neurons (Figures 4 and $5 \mathrm{a}, \mathrm{b})$. In the remaining portion of neurons, no response could be evoked. Increasing the amplitude of fiber stimulation caused a monotonic increase in the amplitude of EPSPs and was capable of driving action potentials in $17 \%(5 / 29)$ of neurons. In one cell, the EPSP was followed by an IPSP. The latency between the stimulus and the onset of the response averaged $4.1 \pm 0.1 \mathrm{~ms}$, with the EPSP reaching its peak amplitude of $10.7 \pm 1.2 \mathrm{mV}$ at $7 \mathrm{~ms}$ following the stimulus.

Perfusion with DA $(30-60 \mu \mathrm{M})$ resulted in a significant reduction in the amplitude of the EPSP obtained by stimulation of the fornix (from $10.7 \pm 1.2$ to $4.5 \pm 1.1 \mathrm{mV}$; $n=12, p<0.001$ ) (Figure 4 , Table 1 ). The reduction of the EPSP amplitude was abolished by the D1 antagonist SCH $23390(10 \mu \mathrm{m} ; 8.6 \pm 1.1 \mathrm{mV}$ compared to control; $p<0.001$; $n=7 ; 3-5 \mu \mathrm{M})$, but not by the D2 antagonist eticlopride 
Table I Effects of DA receptor agonists on EPSP peak amplitude after fornix stimulation and after stimulation of the bed nucleus of the stria terminalis

Dopamine $(n=12)$ DI agonist $(n=12)$ D2 agonist $(n=5)$

\begin{tabular}{|c|c|c|c|}
\hline \multicolumn{4}{|c|}{ After fornix stimulation } \\
\hline Control & $10.7 \pm 1.2 \mathrm{mV}$ & $10.3 \pm 1.8 \mathrm{mV}$ & $9.7 \pm 1.4 \mathrm{mV}$ \\
\hline Drug & $4.5 \pm 1.1 \mathrm{mV} *$ & $3.2 \pm 1.3 \mathrm{mV} *$ & $9.7 \pm 1.2 \mathrm{mV}$ \\
\hline \multicolumn{4}{|c|}{ After stimulation of the bed nucleus of the stria terminalis } \\
\hline & Dopamine $(n=10$ & DI agonist $(n=I I)$ & D2 agonist $(n=4)$ \\
\hline Control & $8.4 \pm 1.5 \mathrm{mV}$ & $8.6 \pm 1.7 \mathrm{mV}$ & $8.5 \pm 1.3 \mathrm{mV}$ \\
\hline Drug & $2.1 \pm 1.2 \mathrm{mV} *$ & $3.5 \pm 1.1 \mathrm{mV} *$ & $6.4 \pm 1.2 \mathrm{mV}$ \\
\hline
\end{tabular}

Paired student's $t$-test; $p<0.001$.*Statistical significance was determined by comparing drug values with predrug control values using a paired t-test, $p<0.00$ l.

$(10 \mu \mathrm{m} ; 10.1 \pm 1.3 \mathrm{mV} ; n=5 ; 10 \mu \mathrm{M})$. In another subset of neurons $(n=12)$, the D1 agonist SKF $38393(10 \mu \mathrm{M})$ reduced the EPSP amplitude in a similar manner as that induced by DA (from $10.3 \pm 1.8$ to $3.2 \pm 1.3 \mathrm{mV} ; p<0.001$ ). In contrast, administration of moderately high doses of the D2 agonist quinpirole $(10 \mu \mathrm{M})$ failed to induce changes in EPSP amplitude $(9.7 \pm 1.4 \mathrm{mV}$ compared to $9.7 \pm 1.2 \mathrm{mV}$; $p>0.01 ; n=5$; Table 1$)$. The neurons returned to near baseline conditions following perfusion with a drug-free solution for 10-20 min (Figures 4 and $7 \mathrm{a}$ ).

In $14 \%(4 / 29)$ of the neurons, the administration of the D1 agonist SKF $38393(10 \mu \mathrm{M})$ induced an increase in the amplitude of the fornix-evoked EPSPs when compared to control $(10.2 \pm 1.2 \mathrm{mV}$ in control; $12.3 \pm 1 \mathrm{mV}$ in the presence of D1 agonist; $p<0.01 ; n=4)$ with the same current intensities (Figure $5 \mathrm{a}, \mathrm{b})$. In one of the cells $(1 / 4)$, the presence of D1 agonist SKF $38393(10 \mu \mathrm{M})$ enabled fornix stimulation to evoke spike discharge following the high intensity stimulus (Figure 5b), whereas stimulation was incapable of evoking spike discharge prior to SKF 38393 administration.

\section{DArgic Modulation of Amygdala-Evoked Responses}

Overall, stimulation of basolateral amygdaloid afferents located in the bed nucleus of the stria terminalis (Figure $3 \mathrm{~b}$ ) evoked EPSPs in 25 out of 38 neurons studied. The latency for the EPSP onset averaged $4.2 \pm 0.2 \mathrm{~ms}$. Increasing the amplitude of afferent stimulation was capable of evoking spikes in only $8 \%(2 / 25)$ of the neurons that responded to the stimulation.

Bath application of DA $(30 \mu \mathrm{M})$ attenuated the amplitude of EPSPs evoked in accumbal neurons following stimulation of the bed nucleus of stria terminalis $(8.4 \pm 1.5-$ $2.1 \pm 1.2 \mathrm{mV} ; n=10$ ) (Figure 6; Table 1). Administration of the D1 antagonist SCH $23390(n=6 ; 3-5 \mu \mathrm{M})$ attenuated the effect of DA $(6.5 \pm 1.3 \mathrm{mV} ; p<0.001)$, whereas the D2 antagonist eticlopride $(10 \mu \mathrm{M})$ was ineffective $(8.1 \pm 1.1 \mathrm{mV}$ compared to control; $n=4)$. In another subset of neurons $(n=11)$, the $\mathrm{D} 1$ agonist SKF $38393(10 \mu \mathrm{M})$ reduced the EPSP amplitude in a similar manner as with DA $(8.6 \pm 1.7-$ $3.5 \pm 1.1 \mathrm{mV} ; p<0.001$ ) (Figure 6, Table 1). Administration of the D2 agonist quinpirole $(10 \mu \mathrm{M} ; n=3)$ failed to induce substantial changes in EPSP amplitude $(8.5 \pm 1.3 \mathrm{mV}$ compared to $6.4 \pm 1.2 \mathrm{mV}$ ) (Table 1). As was the case for hippocampal stimulation, the neurons returned to near baseline conditions following perfusion with a drug-free solution for 10-20 min (Figure 7b).

\section{DISCUSSION}

The major finding of this study was that D1 receptor activation depressed the excitatory postsynaptic responses of the majority of NAc neurons recorded during stimulation of hippocampal and amygdaloid afferents. In a small population of NAc cells (14\%), however, D1 stimulation induced a facilitation of the hippocampus-evoked response. In contrast to results with prefrontal cortical afferent stimulation (O'Donnell and Grace, 1994), D2 stimulation did not attenuate the EPSP amplitude evoked from either the amygdala or hippocampus afferent system. Altogether, these observations indicate a DA receptor subtype-specific modulation of glutamatergic inputs to the NAc, with D2 agonists attenuating PFC drive (O'Donnell and Grace, 1994), and D1 agonists attenuating BLA drive, but with hippocampal-evoked responses showing a bimodal form of modulation by D1 stimulation. a
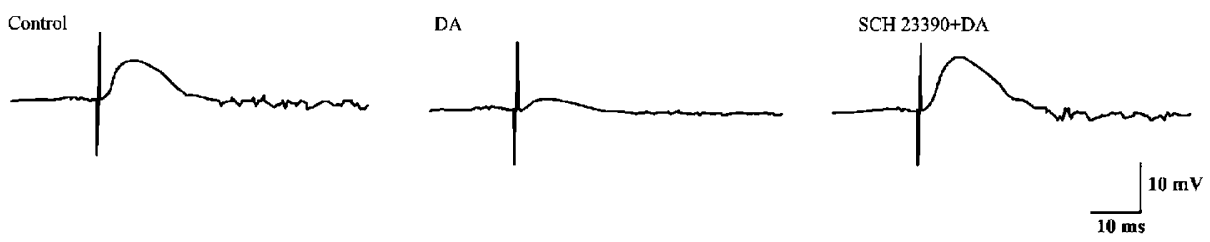

b

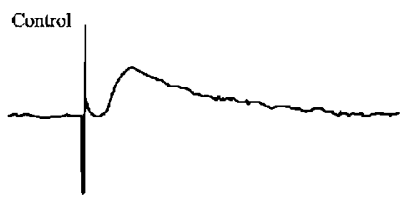

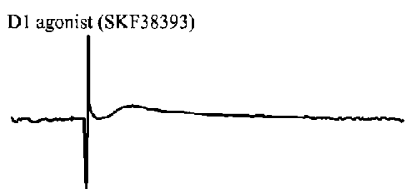

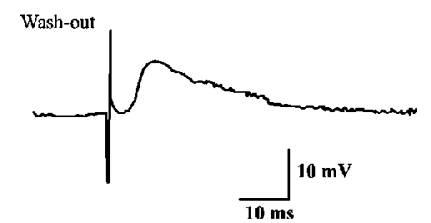

Figure 6 DI receptor stimulation attenuates amygdala-evoked responses. (a) DI receptor antagonist SCH 23390 (3 $\mu$ M) partially reversed the DA $(30 \mu \mathrm{M})$-induced reduction of the EPSP evoked by electrical stimulation of the bed nucleus of stria terminalis. (a) In another cell, the DI receptor agonist SKF $38393(10 \mu \mathrm{M})$ mimicked the effect of DA in that it attenuated the response to amygdaloid fiber stimulation. 


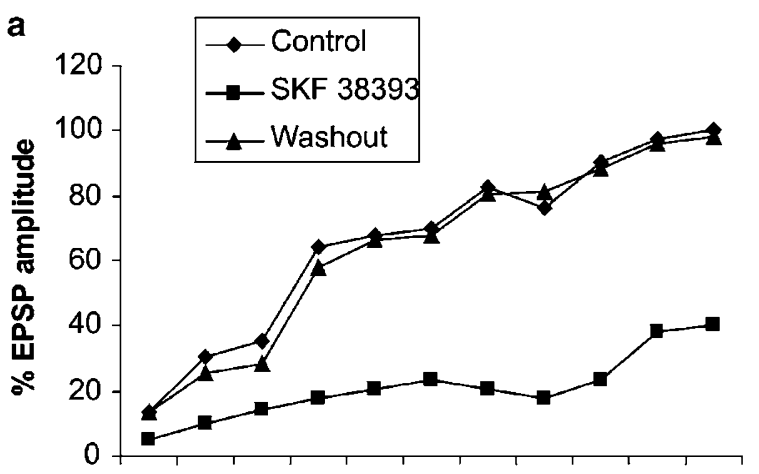

$\begin{array}{lllllllllll}0.1 & 0.2 & 0.3 & 0.4 & 0.5 & 0.6 & 0.7 & 0.8 & 0.9 & 1 & 1.1\end{array}$

Current stimulus (mA)

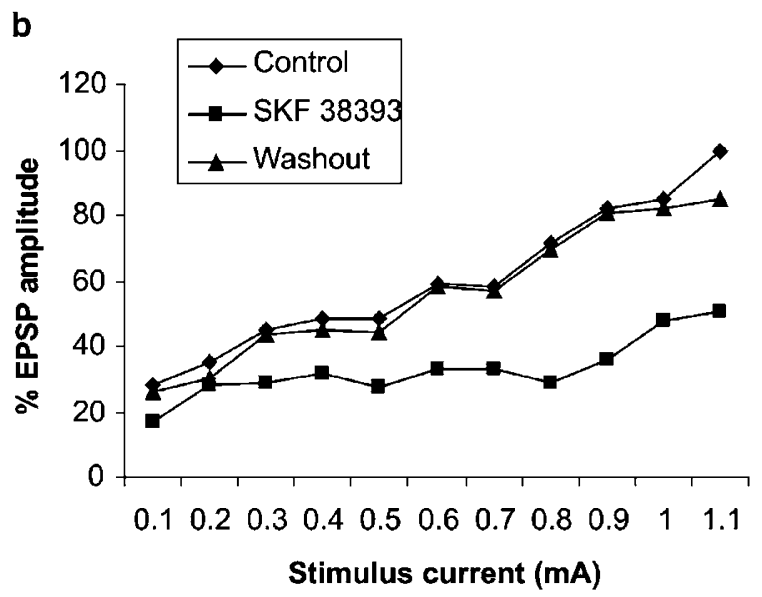

Figure 7 DA effects on NAc postsynaptic responses. (a) Representative curve of the excitatory postsynaptic responses recorded and averaged in NAc neurons after stimulation of the fornix before, during, and after application of the DI agonist SKF 38393. (b) Representative graph of the excitatory postsynaptic responses recorded and averaged in NAc neurons after stimulation of the bed nucleus of stria terminalis, before, during, and after application of the DI agonist SKF 38393. In both the cases (a, b), the EPSPs show a steep rise in amplitude between 0.2 and $0.3 \mathrm{~mA}$ and a gradual saturation close to $1.1 \mathrm{~mA}$. During the application of DI agonist SKF 38393, the EPSP is attenuated for all intensities tested.

\section{NAc Neurons and DA Effects}

Overall, the electrophysiological properties of NAc neurons recorded in this study were similar to those described previously using in vitro intracellular recordings (Chang and Kitai, 1986; Uchimura et al, 1986, 1989; Pennartz and Kitai, 1991; O'Donnell and Grace, 1993). These properties correspond to those of NAc medium spiny projection neurons (Chang and Kitai, 1985; Pennartz et al, 1992a; O'Donnell and Grace, 1993). Perfusion of NAc slices with DA induced a reversible depolarization in most of the neurons tested without changing their input resistance. However, some neurons exhibited either a hyperpolarization or an initial hyperpolarization followed by a depolarization. The administration of the selective D1 agonist induced either a depolarization or an initial hyperpolarization and a subsequent depolarization, whereas administration of the selective D2 agonist induced only a hyperpolarization. These results suggest that the hyperpolarizing and depolarizing actions of DA on NAc neurons are exerted via different DA receptor subtypes. Our findings are consistent with the DA-induced effects observed in previous studies in NAc neurons (Uchimura et al, 1986; O'Donnell and Grace, 1994). However, the exact mechanism underlying the changes observed remains to be established.

\section{Effects of D1-Like Receptor Activation on Excitatory Postsynaptic Responses}

The synaptic responses recorded in NAc shell neurons in response to amygdaloid and hippocampal afferent activation were attenuated by DA in the majority of the cases, although $14 \%$ of the NAc neurons increased EPSP amplitude following fornix stimulation and D1 application. Our results argue strongly that the depressant actions of DA occurred via an action at D1 receptors. Thus, the DAinduced attenuation was substantially blocked by the D1 antagonist SCH 233390, but not by the D2 receptor antagonist eticlopride. Moreover, the selective D1 receptor agonist SKF 38393, but not the D2 receptor agonist quinpirole, mimicked the effects of DA on EPSP amplitude. Consistent with our findings, when stimulating nonidentified afferent fiber bundles in vitro, many other investigators also observed a D1-like receptor-mediated decrease in EPSP amplitude (Higashi et al, 1989; Pennartz et al, 1992b; Harvey and Lacey, 1996, 1997; Nicola et al, 1996; Nicola and Malenka 1997, 1998). In vivo, VTA stimulation or inotophoretically applied DA was found to depress NAc neuron firing evoked by stimulation of the amygdala (Yim and Mogenson, 1982, 1986, 1989) or hippocampus (DeFrance et al, 1985; Yang and Mogenson, 1984, 1986). The finding that D1 antagonist administration did not increase amplitude beyond the predrug baseline suggests that these D1 receptors are not under tonic stimulation in vitro, as found for D2 receptor antagonist actions on PFC afferents (O’Donnell and Grace, 1994).

Our findings that D1 application increases the amplitude of the synaptic response evoked by fornix stimulation in a small population of neurons is in agreement with a recent in vivo study showing a D1-mediated potentiation of hippocampus-evoked spike firing activity (Floresco et al, 2001a). One of several potential reasons for the facilitatory D1 effect is the enhancement of postsynaptic glutamate receptor responsiveness, in particular those mediated by $\mathrm{N}$-methylD-aspartate (NMDA) receptors (Cepeda et al, 1993; Umemiya and Raymond, 1997). In contrast, studies of Yang and Mogenson (1986) suggested the presence of D2-mediated presynaptic effect of DA on these terminals. Whether this is due to differences between in vivo/in vitro preparations or the interactions of D2 drugs with other afferent processes known to be attenuated by D2 receptors (eg PFC-NAc fibers) is unclear.

\section{Mechanism and Site of Action of D1 Receptor Stimulation in the NAc}

The mechanism by which DA D1 receptor activation depresses excitatory transmission evoked in the NAc following stimulation of glutamatergic afferents is the subject of some controversy. The majority of in vitro studies have suggested that the D1 receptor-mediated reduction in EPSP amplitude appears to be a presynaptic 
effect because the paired-pulse facilitation is increased by DA (Pennartz et al, 1992b; Nicola et al, 1996) and DA reduces the frequency of spontaneous miniature EPSCs (Nicola et al, 1996). However, anatomical findings do not support the existence of presynaptic D1 receptors on glutamate terminals in the NAc (Yung et al, 1995). A second proposed mechanism is based on the finding that adenosine A1 receptor antagonists block the effects of DA on EPSPs and that postsynaptic D1 receptor activation increases synaptic NMDA-mediated responses in vitro (Harvey and Lacey, 1997). The authors conclude that the enhanced current flow through the NMDA receptor promotes the production of adenosine that acts as a retrograde trans-synaptic messenger to presynaptically inhibit glutamate release. Floresco et al (2001b) found similar results in which the administration of either D1 or adenosine antagonists blocked the DA-mediated inhibition of BLA-evoked spiking activity in vivo. This hypothesis is consistent with the anatomical localization of $\mathrm{D} 1$ receptors on postsynaptic dendritic spines and shafts of striatal neurons and NAc cells (Huang et al, 1992; Levey et al, 1993; Hersch et al, 1995; Yung et al, 1995; Caille et al, 1996). However, this interpretation has been challenged by Nicola and Malenka (1997), who were unable to replicate the findings that A1 or NMDA receptor antagonists block the DA-induced depression of excitatory synaptic transmission and thus concluded that presynaptic D1 receptors are responsible for this effect. Nonetheless, when considered at the level of DA modulation of interacting systems, our results are consistent in showing a D1-mediated attenuation of amygdaloid and hippocampal afferent inputs to NAc neurons.

\section{Functional Implications}

DA plays a complex role in the gating of afferent input to the NAc, in a manner that depends on the current state of the system. The hippocampal pathway to the NAc has been implicated in exploratory and goal-directed locomotion (Yang and Mogenson, 1987; Burns et al, 1996; Floresco et al, 1997; Bannerman et al, 2001), whereas the amygdala-NAc pathway is believed to play an essential role in mediating affect-facilitation of memory storage (Roozendaal et al, 2001) and approach to conditioned stimuli (Everitt et al, 1991). DA neurotransmission may gate responses of the NAc to particular inputs that in turn may facilitate appropriate behavioral response selection in complex rewarding situations (Mogenson et al, 1993; Floresco et al, 2001a,b). Our previous in vitro and in vivo studies showed that the tonic levels of extracellular DA are sufficient to partially attenuate at least $60 \%$ of PFc afferents to the striatal complex, since administration of a D2 antagonist increases the amplitude of the PFC-evoked response when administered alone (O'Donnell and Grace, 1994; West and Grace, 2002). This was not observed with the D1 antagonist. Given these data, it would appear that enhanced DA neurotransmission can selectively gate afferent interactions in this region. Thus, if DA activation of D2 receptors is actively suppressed or blocked by a D2 antagonist, the input from the PFC would be selectively potentiated relative to hippocampal and amygdaloid inputs. At basal DA levels, stimulation of D2 receptors would attenuate PFC input without inhibiting the hippocampal and amygdaloid afferents (O'Donnell and Grace, 1994), thus shifting the balance toward these subcortical limbic structures. However, with activation of the DA system, increased DA transmission would attenuate most afferent hippocampal and amygdaloid input. The one exception would be its ability to augment a subset of hippocampal-NAc afferents. Given our studies showing that hippocampal/subicular activation will tonically augment VTA DA population activity (Floresco et al, 2001c), such a selective facilitation of an ensemble of hippocampal afferents by D1 receptor activation would permit the hippocampus to have a dominant influence over behavior during periods of exploration (Floresco and Phillips, 1999). In addition, considering that the hippocampus can also facilitate PFC inputs to the NAc (O'Donnell and Grace, 1995), it is possible that facilitation of hippocampal input to the NAc could in turn lead to selective gating of PFc inputs on the same neuron, offsetting the D2-mediated inhibition of this pathway. Thus, during periods of enhanced DA efflux, hippocampal inputs conveying contextual information about the environment could permit a selective gating of PFc inputs which can lead to specific patterns of behavior that are appropriate to that context.

\section{ACKNOWLEDGEMENTS}

This work was supported by United States Public Health Service Grants MH, 45156, 57440 (AAG) and National Alliance for Research on Schizophrenia and Depression (AC). We thank Dr Hank Jedema for his help with the in vitro slice recordings. We also thank Nicole MacMurdo and Christy Wyant for their technical assistance, and Brian Lowry for the development of software (Neuroscope) used in data acquisition. We are grateful to Drs Holly Moore, Stan Floresco and Anthony West for their valuable comments, suggestions, and enlightening discussions regarding this manuscript.

\section{REFERENCES}

Alvarez P, Zola-Morgan S, Squire LR (1995). Damage limited to the hippocampal region produces long-lasting memory impairment in monkeys. J Neurosci 15: 3796-3807.

Bannerman DM, Gilmour G, Norman G, Lemaire M, Iversen SD, Rawlins JN (2001). The time course of the hyperactivity that follows lesions or temporary inactivation of the fimbria-fornix. Behav Brain Res 120: 1-11.

Berendse HW, Groenewegen HJ (1990). Organization of the thalamostriatal projections in the rat, with special emphasis on the ventral striatum. J Comp Neurol 299: 187-228.

Bouyer JJ, Joh TH, Pickel VM (1984). Ultrastructural localization of tyrosine hydroxylase in rat nucleus accumbens. J Comp Neurol 227: 92-103.

Burns LH, Annett L, Kelley AE, Everitt BJ, Robbins TW (1996). Effects of lesions to amygdala, ventral subiculum, medial prefrontal cortex, and nucleus accumbens on the reaction to novelty: implication for limbic-striatal interactions. Behav Neurosci 110: 60-73.

Caille I, Dumartin B, Bloch B (1996). Ultrastructural localization of D1 dopamine receptor immunoreactivity in rat striatonigral neurons and its relation with dopaminergic innervation. Brain Res 730: 17-31. 
Callaway CW, Hakan RL, Henriksen SJ (1991). Distribution of amygdala input to the nucleus accumbens septi: an electrophysiological investigation. J Neural Transm 83: 215-225.

Canteras NS, Swanson LW (1992). Projections of the ventral subiculum to the amygdala, septum, and hypothalamus: a PHAL anterograde tract-tracing study in the rat. J Comp Neurol 324: 180-194.

Chang HT, Kitai ST (1986). Intracellular recordings from rat nucleus accumbens neurons in vitro. Brain Res 366: 392-396.

Charara A, Grace AA (2001). Mesolimbic dopamine modulates hippocampus- and amygdala evoked responses in rat nucleus accumbens: an in vitro study. Soc Neurosci Abstr 27: 918.9.

Cepeda C, Buchwald NA, Levine MS (1993). Neuromodulatory actions of dopamine in the neostriatum are dependent upon the excitatory amino acid receptor subtypes activated. Proc Natl Acad Sci USA 90: 9576-9580.

Chang HT, Kitai ST (1985). Projection neurons of the nucleus accumbens: an intracellular labeling study. Brain Res 347: $112-116$.

Davis M (1992). The role of the amygdala in fear and anxiety. Annu Rev Neurosci 15: 353-375.

DeFrance JF, Marchand JF, Sikes RW, Chronister RB, Hubbard JI (1985). Charcaterization of fimbria input to nucleus accumbens. J Neurophysiol 54: 1553-1567.

Descarries L, Watkins KC, Garcia S, Bosler O, Doucet G (1996). Dual character, asynaptic and synaptic, of the dopamine innervation in adult rat neostriatum: a quantitative autoradiographic and immunocytochemical analysis. J Comp Neurol 375: 167-186.

Everitt BJ, Morris KA, O'Brien A, Robbins TW (1991). The basolateral amygdala-ventral striatal system and conditioned place preference: further evidence of limbic-striatal interactions underlying reward-related processes. Neuroscience 42: 1-18.

Finch DM (1996). Neurophysiology of converging synaptic inputs from the rat prefrontal cortex, amygdala, midline thalamus, and hippocampal formation onto single neurons of the caudate/ putamen and nucleus accumbens. Hippocampus 6: 495-512.

Floresco SB, Blaha CD, Yang CR, Phillips AG (2001a). Modulation of hippocampal and amygdalar-evoked activity of nucleus accumbens neurons by dopamine: cellular mechanisms of input selection. J Neurosci 21: 2851-2860.

Floresco SB, Blaha CD, Yang CR, Phillips AG (2001b). Dopamine D1 and NMDA receptors mediate potentiation of basolateral amygdala-evoked firing of nucleus accumbens neurons. $J$ Neurosci 21: 6370-6376.

Floresco SB, Phillips AG (1999). Dopamine and hippocampal input to the nucleus accumbens play an essential role in the search for food in an unpredictable environment. Psychobiology 27: 277286.

Floresco SB, Seamans JK, Phillips AG (1997). Selective roles for hippocampal, prefrontal cortical, and ventral striatal circuits in radial-arm maze tasks with or without a delay. J Neurosci 17: $1880-1890$

Floresco SB, Todd CL, Grace AA (2001c). Glutamatergic afferents from the hippocampus to the nucleus accumbens regulate activity of ventral tegmental area dopamine neurons. J Neurosci 21: 4915-4922.

Garris PA, Ciolkowski EL, Pastore P, Wightman RM (1994). Efflux of dopamine from the synaptic cleft in the nucleus accumbens of the rat brain. J Neurosci 14: 6084-6093.

Grace AA (1991). Phasic versus tonic dopamine release and the modulation of dopamine system responsivity: a hypothesis for the etiology of schizophrenia. Neuroscience 41: 1-24.

Groenewegen HJ, Vermeulen-Van der Zee E, te Kortschot A, Witter MP (1987). Organization of the projections from the subiculum to the ventral striatum in the rat. A study using anterograde transport of Phaseolus vulgaris leucoagglutinin. Neuroscience 23: 103-120.
Groenewegen HJ, Wright CI, Beijer AV, Voorn P (1999). Convergence and segregation of ventral striatal inputs and outputs. Ann NY Acad Sci 877: 49-63.

Harvey J, Lacey MG (1996). Endogenous and exogenous dopamine depress EPSCs in rat nucleus accumbens in vitro via D1 receptor activation. J Physiol 492: 143-154.

Harvey J, Lacey MG (1997). A postsynaptic interaction between dopamine D1 and NMDA receptors promotes presynaptic inhibition in the rat nucleus accumbens via adenosine release. J Neurosci 175271-175280.

Heimer L, Alheid GF (1991). Piecing together the puzzle of basal forebrain anatomy. Adv Exp Med Biol 295: 1-42.

Hersch SM, Ciliax BJ, Gutekunst CA, Rees HD, Heilman CJ, Yung KK et al (1995). Electron microscopic analysis of D1 and D2 dopamine receptor proteins in the dorsal striatum and their synaptic relationships with motor corticostriatal afferents. $J$ Neurosci 15: 5222-5237.

Higashi H, Inanaga K, Nishi S, Uchimura N (1989). Enhancement of dopamine actions on rat nucleus accumbens neurones in vitro after methamphetamine pre-treatment. J Physiol 408: 587-603.

Huang Q, Zhou D, Chase K, Gusella JF, Aronin N, DiFiglia M (1992). Immunohistochemical localization of the D1 dopamine receptor in rat brain reveals its axonal transport, pre- and postsynaptic localization, and prevalence in the basal ganglia, limbic system, and thalamic reticular nucleus. Proc Natl Acad Sci USA 89: 11988-11992.

Hyman SE (1996). Addiction to cocaine and amphetamine. Neuron 16: 901-904.

Iversen SD (1995). Interactions between excitatory amino acids and dopamine systems in the forebrain: implications for schizophrenia and Parkinson's disease. Behav Pharmacol 6: 478-491.

Jay TM, Witter MP (1991). Distribution of hippocampal CA1 and subicular efferents in the prefrontal cortex of the rat studied by means of anterograde transport of Phaseolus vulgaris-leucoagglutinin. J Comp Neurol 313: 574-586.

Kalivas PW, Sorg BA, Hooks MS (1993). The pharmacology and neural circuitry of sensitization to psychostimulants. Behav Pharmacol 4: 315-334.

Kelley AE, Domesick VB (1982). The distribution of the projection from the hippocampal formation to the nucleus accumbens in the rat: an anterograde- and retrograde-horseradish peroxidase study. Neuroscience 7: 2321-2335.

Kelley AE, Domesick VB, Nauta WJ (1982). The amygdalostriatal projection in the rat - an anatomical study by anterograde and retrograde tracing methods. Neuroscience 7: 615-630.

Lavin A, Grace AA (1994). Modulation of dorsal thalamic cell activity by the ventral pallidum: its role in the regulation of thalamocortical activity by the basal ganglia. Synapse 18: 104-127.

LeDoux JE (1993). Emotional memory systems in the brain. Behav Brain Res 58: 69-79.

Levey AI, Hersch SM, Rye DB, Sunahara RK, Niznik HB, Kitt CA et al (1993). Localization of D1 and D2 dopamine receptors in brain with subtype-specific antibodies. Proc Natl Acad Sci USA 90: 8861-8865.

McDonald AJ (1991). Topographical organization of amygdaloid projections to the caudate putamen, nucleus accumbens, and related striatal-like areas of the rat brain. Neuroscience 44: 15-33.

Mogenson GJ, Brudzynski SM, Wu M, Yang CR, Yim CY (1993). From motivation to action: a review of dopamine regulation of limbic-nucleus accumbens-ventral pallidum-pedunculopontine nucleus circuitries involved in limbic-motor integration. In: Kalivas PW, Barnes CD (eds) Limbic Motor Circuits and Neuropsyciatry. CRC Press: Boca Raton, FL. pp 193-236.

Mulder AB, Hodenpijl MG, Lopes da Silva FH (1998). Electrophysiology of hippocampal and amygdaloid projections to the 
nucleus accumbens of the rat: convergence, segregation, and interaction of inputs. J Neurosci 18: 5095-5102.

Nauta WJ, Smith GP, Faull RL, Domesick VB (1978). Efferent connections and nigral afferents of the nucleus accumbens septi in the rat. Neuroscience 3: 385-401.

Nicola SM, Kombian SP, Malenka RC (1996). Psychostimulants depress excitatory synaptic transmission in the nucleus accumbens via presynaptic D1-like dopamine receptors. J Neurosci 16: 1591-1604.

Nicola SM, Malenka RC (1997). Dopamine depresses excitatory and inhibitory synaptic transmission by distinct mechanisms in the nucleus accumbens. J Neurosci 17: 5697-5710.

Nicola SM, Malenka RC (1998). Modulation of synaptic transmission by dopamine and norepinephrine in ventral but not dorsal striatum. J Neurophysiol 79: 1768-1776.

Nicola SM, Surmeier J, Malenka RC (2000). Dopaminergic modulation of neuronal excitability in the striatum and nucleus accumbens. Annu Rev Neurosci 23: 185-215.

O’Donnell P, Grace AA (1993). Physiological and morphological properties of accumbens core and shell neurons recorded in vitro. Synapse 13: 135-160.

O'Donnell P, Grace AA (1994). Tonic D2-mediated attenuation of cortical excitation in nucleus accumbens neurons recorded in vitro. Brain Res 634: 105-112.

O’Donnell P, Grace AA (1995). Synaptic interactions among excitatory afferents to nucleus accumbens neurons: hippocampal gating of prefrontal cortical input. J Neurosci 15: 3622-3639.

O’Donnell P, Grace AA (1996). Dopaminergic reduction of excitability in nucleus accumbens neurons recorded in vitro. Neuropsychopharmacology 15: 87-97.

Paxinos G, Watson C 1986. The Rat Brain in Stereotaxic Coordinates. Academic Press: New York.

Pennartz CM, Dolleman-van Der Weel MJ, Kitai ST, Lopes da Silva FH (1992a). Differential membrane properties and dopamine effects in the shell and core of the rat nucleus accumbens studied in vitro. Neurosci Lett 136: 109-112.

Pennartz CM, Dolleman-van Der Weel MJ, Kitai ST, Lopes da Silva FH (1992b). Presynaptic dopamine D1 receptors attenuate excitatory and inhibitory limbic inputs to the shell region of the rat nucleus accumbens studied in vitro. J Neurophysiol 67: $1325-1334$.

Pennartz CM, Groenewegen HJ, Lopes da Silva FH (1994). The nucleus accumbens as a complex of functionally distinct neuronal ensembles: an integration of behavioural, electrophysiological and anatomical data. Prog Neurobiol 42: 719-761.

Pennartz CM, Kitai ST (1991). Hippocampal inputs to identified neurons in an in vitro slice preparation of the rat nucleus accumbens: evidence for feed-forward inhibition. J Neurosci 11: 2838-2847.

Robbins TW, Everitt BJ (1996). Neurobehavioural mechanisms of reward and motivation. Curr Opin Neurobiol 6: 228-236.

Roozendaal B, de Quervain DJ, Ferry B, Setlow B, McGaugh JL (2001). Basolateral amygdala-nucleus accumbens interactions in mediating glucocorticoid enhancement of memory consolidation. J Neurosci 21: 2518-2525.

Sesack SR, Deutch AY, Roth RH, Bunney BS (1989). Topographical organization of the efferent projections of the medial prefrontal cortex in the rat: an anterograde tract-tracing study with Phaseolus vulgaris leucoagglutinin. J Comp Neurol 290: 213-242.

Sesack SR, Pickel VM (1990). In the rat medial nucleus accumbens, hippocampal and catecholaminergic terminals converge on spiny neurons and are in apposition to each other. Brain Res 527: 266-279.

Sesack SR, Pickel VM (1992). Prefrontal cortical efferents in the rat synapse on unlabeled neuronal targets of catecholamine terminals in the nucleus accumbens septi and on dopamine neurons in the ventral tegmental area. J Comp Neurol 320: $145-160$

Uchimura N, Higashi H, Nishi S (1986). Hyperpolarizing and depolarizing actions of dopamine via D-1 and D-2 receptors on nucleus accumbens neurons. Brain Res 375: 368-372.

Uchimura N, Higashi H, Nishi S (1989). Membrane properties and synaptic responses of the guinea pig nucleus accumbens neurons in vitro. J Neurophysiol 61: 769-779.

Umemiya M, Raymond LA (1997). Dopaminergic modulation of excitatory postsynaptic currents in rat neostriatal neurons. J Neurophysiol 78: 1248-1255.

West AR, Grace AA (2002). Opposite influences of endogenous dopamine D1 and D2 receptor activation on activity states and electrophysiological properties of striatal neurons: studies combining in vivo intracellular recordings and reverse microdialysis. J Neurosci 22: 294-304.

Yang CR, Mogenson GJ (1984). Electrophysiological responses of neurons in the nucleus accumbens to hippocampal stimulation and the attenuation of the excitatory responses by the mesolimbic dopaminergic system. Brain Res 324: 69-84.

Yang CR, Mogenson GJ (1986). Dopamine enhances terminal excitability of hippocampal-accumbens neurons via D2 receptor: role of dopamine in presynaptic inhibition. $J$ Neurosci 6: 2470-2478.

Yang CR, Mogenson GJ (1987). Hippocampal signal transmission to the pedunculopontine nucleus and its regulation by dopamine D2 receptors in the nucleus accumbens: an electrophysiological and behavioural study. Neuroscience 23: 1041-1055.

Yim CH, Mogenson GJ (1982). Response of nucleus accumbens neurons to amygdala stimulation and its modification by dopamine. Brain Res 239: 401-415.

Yim CH, Mogenson GJ (1986). Mesolimbic dopamine projection modulates amygdala-evoked EPSP in nucleus accumbens neurons: an in vivo study. Brain Res 369: 347-352.

Yim CH, Mogenson GJ (1989). Low doses of accumbens dopamine modulate amygdala suppression of spontaneous exploratory activity in rats. Brain Res 477: 202-210.

Yung KK, Bolam JP, Smith AD, Hersch SM, Ciliax BJ, Levey AI (1995). Immunocytochemical localization of D1 and D2 dopamine receptors in the basal ganglia of the rat: light and electron microscopy. Neuroscience 65: 709-730. 